\title{
Phylogenetic analysis of three orf virus strains isolated from different districts in Shandong Province, East China
}

\author{
Kaizhao ZHANG ${ }^{1 \#}$, Yihong XIAO ${ }^{2 \#}$, Meng YU ${ }^{1)}$, Jianxin LIU ${ }^{1)}$, Qingnan WANG ${ }^{1)}$, Pan TAO ${ }^{1)}$, Sidang LIU $^{2) *}$ and \\ Zhangyong $\mathrm{NING}^{1,3) *}$ \\ ${ }^{1)}$ College of Veterinary Medicine, South China Agricultural University, Guangzhou 510642, People 's Republic of China \\ ${ }^{2)}$ College of Animal Science and Technology, Shandong Agricultural University, Tai'an, 271018, People's Republic of China \\ ${ }^{3)}$ Key Laboratory of Prevention and Control for Severe Clinical Animal Diseases, Guangzhou, Guangdong Province, 510642, People's \\ Republic of China
}

(Received 22 June 2015/Accepted 19 July 2015/Published online in J-STAGE 27 August 2015)

ABSTRACT. Orf virus (ORFV) is the causative agent of contagious ecthyma, which is a zoonotic disease that affects sheep, goats, wild small ruminants and humans. Shandong Province in East China is one of the main producing areas in China for sheep and goats. Here, we conducted epidemiological surveys in different areas in this Province, isolated three orf virus strains, SDLC, SDTA and SDJN, from goat flocks and then analyzed the genetic evolution of these strains. The ORFV011, ORFV059, ORFV109, ORFV110 and ORFV127 genes of these three strains were amplified, sequenced and analyzed. Phylogenetic analysis showed that ORFV011 of the SDLC and SDTA strains cluster together with the Gansu, Liaoning, Shanxi, Nantou, Hoping and FJ-YX strains, while SDJN clusters with the FJ-GS and FJ-GO strains. ORFV059 of the SDLC and SDTA strains cluster together with the FJ-YX strain, while SDJN clusters with the FJ-GS and FJ-GO strains. ORFV059 and ORFV127 of these three strains were similar to those of the OV-SA00 strain. The results suggested that SDLC, SDTA and SDJN originated from Fujian Province and formed a complex group of viruses in Shandong Province. As the role of ORFV127 gene responsible for the immune evasion of ORFV, the pathogenesis of these three virus strains may similar to that of OV-SA00. These three strains first isolated in Shandong Province are novel ORFV strains, and the data reported here will be helpful for further research about ORFV and its comprehensive prevention and control.

KEY WORDS: East China, goat, Orf virus, phylogenetic analysis, Shandong Province

doi: 10.1292/jvms.15-0368; J. Vet. Med. Sci. 77(12): 1639-1645, 2015

Orf disease, also named contagious ecthyma (CE), is a zoonotic disease that affects sheep, goats, wild small ruminants and humans in all sheep-breeding countries [2, 11, 12]. Clinically, proliferative and self-limiting maculopapular and vesicular pustules occur in the epithelium of the lips, mouth, muzzle, nose, and even in the teat, udder, esophagus or other organs $[2,7,11,12]$. Orf disease has high morbidity but usually low mortality, while it also shows high fatality due to secondary infection or extreme debilitating condition [12, 35]. Orf virus (ORFV) is the causative agent of this disease and is the prototype member of the genus Parapoxvirus, which includes pseudocowpox virus (PCPV), bovine papular stomatitis virus (BPSV), squirrel parapoxvirus (SPPV) and parapoxvirus of red deer in New Zealand (PVNZ) [12, 19, 35]. The genome of ORFV is a linear double-stranded DNA of 134-139 kb in length that encodes 132 putative

*Correspondence to: Liu, S., College of Animal Science and Technology, Shandong Agricultural University, Tai' an, 271018, People's Republic of China. e-mail: liusid@sdau.edu.cn, Ning, Z., College of Veterinary Medicine, South China Agricultural University, Guangzhou 510642, People's Republic of China.

e-mail: ningzhyong@scau.edu.cn

\#These authors contributed equally to this work.

C2015 The Japanese Society of Veterinary Science

This is an open-access article distributed under the terms of the Creative Commons Attribution Non-Commercial No Derivatives (by-nc-nd) License $<$ http://creativecommons.org/licenses/by-nc-nd/3.0/>. genes including 89 highly conserved genes essential for viral structure and assembly located in the core region of the genome and variable genes responsible for virus virulence and pathogenesis at the terminal regions $[8,25]$.

Although the genomes of OV-IA 82 and OV-SA00 in America [8], NZ2 in New Zealand [25], D1701 in Germany [24] and NA1/11 in China [21] have been completely sequenced, there is still little information on the characterization of endemic ORFV strains in mainland China given its large scale. To date, most genetic variation and molecular epidemiology of the orf virus has been based on the highly conserved genes of ORFV011 (B2L), ORFV059 (F1L) and/or ORFV020 (VIR) $[1,17,20,31]$. ORFV field strains have different levels of heterogeneity even in the same place [6], and the relationship between disease severity and the molecular characterization of ORFV strains has not been fully elucidated.

In spite of the fact that ORFV infections have been reported in Xiangjiang, Fujian, Gansu and Jilin Provinces in China $[6,20,31,35]$, there is a lack of genetic data on circulating ORFV strains in Shandong Province in East China, which is adjacent to Japan and Korea and the top mutton production area in China. Here, we isolated and identified ORFV strains in Shandong Province of China. Genetic diversity was also determined by comparing the full lengths of the ORFV011, ORFV059, ORFV109, ORFV110 and ORFV127 genes with reference strains in GenBank. This is the first phylogenetic analysis of orf virus strains isolated from different districts in Shandong Province, East China. 
Table 1. Clinical and epidemiological information for the ORFV strains analyzed in this research

\begin{tabular}{|c|c|c|c|c|c|c|}
\hline Strains & Species & $\begin{array}{c}\text { Goats } \\
\text { affected/total }\end{array}$ & $\begin{array}{l}\text { Sites of } \\
\text { lesions }\end{array}$ & $\begin{array}{l}\text { Districts of Shandong } \\
\text { Province }\end{array}$ & Year & Deposited Accession No. in GenBank \\
\hline SDLC & Goat & $4 / 30$ & Lips & Liaocheng City & 2013 & $\begin{array}{l}\text { ORFV011, KP339952; ORFV059, KP339950 } \\
\text { ORFV109, KP339948; ORFV110, KP339946, } \\
\text { ORFV127, KP339944 }\end{array}$ \\
\hline SDTA & Goat & $15 / 40$ & Lips, feet & Tai'an City & 2014 & $\begin{array}{l}\text { ORFV011, KP339951; ORFV059, KP339949, } \\
\text { ORFV109, KP339947; ORFV110, KP339945, } \\
\text { ORFV127, KP339943 }\end{array}$ \\
\hline SDJN & Goat & $7 / 60$ & Lips & Jining City & 2014 & $\begin{array}{l}\text { ORFV011, KP336709; ORFV059, KP336710 } \\
\text { ORFV109, KP336711; ORFV110, KP336712 } \\
\text { ORFV127, KP336713 }\end{array}$ \\
\hline
\end{tabular}

\section{MATERIALS AND METHODS}

Sheep herds and tissue collection: Skin biopsies with gross pathologic changes were collected from goat flocks that had typical clinical features of orf disease, including papules, pustules and scabs, in Shandong Province from 2013 to 2014. Clinical and epidemiological information of ORFV isolates analyzed in this research are shown in Table 1. Samples were collected as described in our previous reports $[19,22]$ and stored in sterile tubes at $-80^{\circ} \mathrm{C}$ for virus isolation and polymerase chain reaction (PCR). From 2013 to 2014, 26 samples from these flocks were collected, and three virus strains were isolated from them.

$D N A$ extraction, polymerase chain reaction (PCR) and sequencing: DNA extraction, PCR, sequencing and isolation of orf virus using primary ovine fetal turbinate (OFTu) cells were performed as described in our previous reports $[19,22,26]$. Briefly, total DNA was extracted from $200 \mu l$ of cell culture suspensions using a QIAamp DNA Blood Mini Kit (QIAGEN, Hilden, Germany) according to the manufacturer's instructions. To amplify the entire open reading frame of the two highly conserved genes ORFV011 (B2L) and ORFV059 (F1L), and three variable genes, ORFV109, ORFV110 (EEV) and ORFV127 (vIL-10), five sets of primer pairs were designed and synthesized based on the ORFV genomic sequences $[8,22]$. The sequences of the primers were as follows: ORFV011, 5'- ATGTGGCCGT TCTCCTCTATC-3' (forward) and 5'-TTAATTTATTGGCTTGCAG-3' (reverse); ORFV059, 5'-ATGGATCCACCCGAAATCAC-3' (forward) and 5'-TCACACGAT GGCCGTGACCAG-3' (reverse); ORFV109, 5'- ATGGCACATAACACGTTC-3' (forward) and 5'-CTAACCAGACACACAAA-3' (reverse); ORFV110, 5'- ATGGGTTGCTGTAAGGT C- 3' (forward) and $5^{\prime}$-TTATCCGTGCATCTCCTTC-3' (reverse); and ORFV127, 5'-CAATT GGAATGTCGAAGAAC-3' (forward) and 5'-AGCAGAACGATACGAGAATCCGAAC-3' (reverse). The genes were amplified by PCR in a $50 \mu \mathrm{l}$ reaction volume under the following conditions: 36 cycles of denaturation at $95^{\circ} \mathrm{C}$ for $30 \mathrm{sec}$, annealing at $60^{\circ} \mathrm{C}$ for $40 \mathrm{sec}$ for $O R F V 011$ and $O R F V 059$, and at $58^{\circ} \mathrm{C}$ for $40 \mathrm{sec}$ for ORFV109, ORFV110 and ORFV127, and extension at $72^{\circ} \mathrm{C}$ for $90 \mathrm{sec}$, with a final PCR ending with one extension cycle at $72^{\circ} \mathrm{C}$ for $10 \mathrm{~min}$. The amplified DNA products were purified with a Gel Extraction Kit (Takara Biotech, Dalian,
China), subcloned into pMD18-T vector (Takara Biotech) and sequenced.

Phylogenetic analysis: The nucleotide sequences of ORFV011, ORFV059, ORFV109, ORFV110 and ORFV127 of SDLC, SDTA, SDJN and other isolated strains used for phylogenetic analysis in this research were obtained from GenBank (http://www.ncbi.nlm.nih.gov/Genbank/) and are listed in Table 2. Sequence editing, alignment and comparison of the sequences were performed by using Clustal W (http://www.clustal.org/clustal2/). Phylogenetic trees were constructed with the MEGA 5 software using the Kimura-2 parameter evolution model and the neighbor-joining method with 1,000 bootstrap replicates to calculate pairwise distances.

\section{RESULTS}

Products of PCR amplification: The full sequences of ORFV011, ORFV059, ORFV109, ORFV110 and ORFV127 were successfully amplified by PCR. The sizes of the amplicons were $1137,1029,498,480$ and 558 bp, respectively. The amplified products were purified and ligated into pMD18-T vectors. At least three different clones of each gene were amplified and sequenced bidirectionally. The sequences were edited, aligned and deposited in GenBank. Fifteen accession numbers for ORFV011, ORFV059, ORFV109, ORFV110 and ORFV127 of these three ORFV strains are listed in Table 1.

Phylogenetic analysis: To analyze and determine the phylogenetic evolutionary relationship of SDLC, SDTA and SDJN with other ORFV strains, including PCPV and BPSV, the corresponding sequences obtained from GenBank were used in this study, and they are presented in Table 2.

The ORFV011 and ORFV059 sequences of the three isolated Orf viruses shared $97.1-98.4 \%$ and $95.8-97.5 \%$ nucleotide identities and 97.6-99.2\% and 95.3-98.8\% deduced amino acid identities with published reference ORFV strains (Table 3). Furthermore, ORFV127 also showed high identity, that is, $95.5-98.2 \%$ at the nucleotide level and 91.9-98.4\% at the amino acid level.

Phylogenetic consensus trees were constructed by MEGA 5.0 based on the alignment results of nucleotides of ORFV011, ORFV059 and ORFV127. ORFV011 of the SDLC and SDTA strains clustered together with those of the Gansu, Liaoning, Shanxi, Nantou, Hoping and FJ-YX strains. ORFV011 
Table 2. Strains of parapoxvirus used in phylogenetic analysis

\begin{tabular}{|c|c|c|c|c|c|}
\hline Accession No. in GenBank & Strains & Country & Host species & Genes & Reference \\
\hline JQ619903/JQ619904 & NA1/11 & China & Sheep & $011 / 059 / 127$ & Li et al. [22] \\
\hline KC568400/KC568411 & FJ-ZX & China & Goat & $011 / 059$ & Chi et al. [6] \\
\hline KC568399/KC568410 & FJ-YX & China & Goat & $011 / 059$ & Chi et al. [6] \\
\hline KC568398/KC568409 & FJ-SL & China & Goat & $011 / 059$ & Chi et al. [6] \\
\hline KC568394/KC568405 & FJ-GT & China & Goat & $011 / 059$ & Chi et al. [6] \\
\hline KC568393/KC568404 & FJ-GS & China & Goat & $011 / 059$ & Chi et al. [6] \\
\hline KC568392/KC568403 & FJ-GO & China & Goat & $011 / 059$ & Chi et al. [6] \\
\hline KC568391/KC568402 & FJ-FQ & China & Goat & $011 / 059$ & Chi et al. [6] \\
\hline KC568390/KC568401 & FJ-DS & China & Goat & $011 / 059$ & Chi et al. [6] \\
\hline KM583893/KM583894 & GDQY & China & Goat & $011 / 059$ & Duan et al. [9] \\
\hline DQ184476 & NZ2 & New Zealand & Sheep & $011 / 059 / 127$ & Mercer et al. [25] \\
\hline HM133903 & D1701 & Germany & Sheep & $011 / 059 / 127$ & McGuire et al. [24] \\
\hline AY386263 & OV-IA82 & U.S.A. & Lamb & $011 / 059 / 127$ & Delhon et al. [8] \\
\hline AY386264 & OV-SA00 & U.S.A. & Sheep & $011 / 059 / 127$ & Delhon et al. [8] \\
\hline FJ808074 & Jilin & China & Sheep & 011 & Zhao et al. [35] \\
\hline KC485343 & Gansu & China & Human & 011 & Zhang et al. [32] \\
\hline HQ694773 & LiaoNing/2010 & China & Goat & 011 & Unpublished \\
\hline GU320351 & $\mathrm{HuB} / 2009$ & China & Goat & 011 & Zhang et al. [34] \\
\hline HQ694772 & GanSu/2009 & China & Sheep & 011 & Unpublished \\
\hline KF703747/KC291656 & Xinjiang & China & Goat & $011 / 059$ & Unpublished \\
\hline GU903501 & JS04 & China & Sheep & 011 & Liu et al. [23] \\
\hline HQ202153 & Shanxi & China & Goat & 011 & Unpublished \\
\hline JN613809 & MT-05 & Brazil & Sheep & 011 & Unpublished \\
\hline GQ328006 & 2009/Korea & South Korea & Goat & 011 & Oem et al. [28] \\
\hline JQ904797 & $\mathrm{CQ} / \mathrm{WZ}$ & China & Goat & 011 & Zhang et al. [33] \\
\hline GU139356 & Mukteswar/09 & India & Sheep & 011 & Unpublished \\
\hline DQ263305 & $67 / 04$ & India & Sheep & 011 & Hosamani et al. [15] \\
\hline DQ263306 & $79 / 04$ & India & Sheep & 011 & Hosamani et al. [15] \\
\hline DQ263304 & $59 / 05$ & India & Goat & 011 & Hosamani et al. [15] \\
\hline DQ263303 & $82 / 04$ & India & Goat & 011 & Hosamani et al. [15] \\
\hline EU327506 & Taiping & Taiwan & Goat & 011 & Chan et al. [5] \\
\hline DQ904351 & Nantou & Taiwan & Goat & 011 & Chan et al. [4] \\
\hline EU935106 & Hoping & Taiwan & Goat & 011 & Chan et al. [3] \\
\hline AY424969 & Musk ox & U.S.A. & Musk ox & 011 & Guo et al. [11] \\
\hline JN613810 & NE1 & Brazil & Goat & 011 & Unpublished \\
\hline JN088051 & NE2 & Brazil & Goat & 011 & Unpublished \\
\hline AY424972 & PCPV TQ & U.S.A. & Cow & 011 & Guo et al. [11] \\
\hline GQ329670 & PCPV VR634 & New Zealand & Reindeer & $011 / 059$ & Hautaniemi et al. [13] \\
\hline GQ329669 & PCPV F00.120R & Finland & Reindeer & $011 / 059$ & Hautaniemi et al. [13] \\
\hline JF773692 & PCPV F07.798R & Finland & Reindeer & 011 & Hautaniemi et al. [14] \\
\hline JF773694 & PCPV F05.990C & Finland & Bovine & 011 & Hautaniemi et al. [14] \\
\hline JF773695 & PCPV F10.3081C & Finland & Bovine & 011 & Hautaniemi et al. [14] \\
\hline AY424973 & BPSV RS & U.S.A. & Calf & 011 & Guo et al. [11] \\
\hline AY386265 & BPSV BV-AR02 & U.S.A. & Calf & $011 / 059$ & Delhon et al. [8] \\
\hline JQ271535 & Jilin-Nongan & China & Sheep & 059 & Wang et al. [29] \\
\hline JX142183 & GanS/2010 & China & NA & 059 & Unpublished \\
\hline AY040083 & $\mathrm{OV} / \mathrm{C} 2$ & Italy & Sheep & 059 & Unpublished \\
\hline AY040082 & $\mathrm{OV} / \mathrm{mi}-90$ & Italy & Sheep & 059 & Unpublished \\
\hline AY040081 & OV/Torino & Italy & Sheep & 059 & Unpublished \\
\hline \multirow[t]{4}{*}{ AY040085 } & $\mathrm{OV} / 20$ & Italy & Sheep & 059 & Unpublished \\
\hline & SDLC & China & Goat & $011 / 059 / 127$ & Present study \\
\hline & SDTA & China & Goat & $011 / 059 / 127$ & Present study \\
\hline & SDJN & China & Goat & $011 / 059 / 127$ & Present study \\
\hline
\end{tabular}


Table 3. The identity of nucleotide and amino acid sequences of SDLC, SDTA and SDJN with the references ORFV strains

\begin{tabular}{|c|c|c|c|c|c|c|}
\hline \multirow{2}{*}{$\begin{array}{l}\text { Strain and its Geninfo Identifier } \\
\text { (gi) }\end{array}$} & \multicolumn{2}{|c|}{ SDLC } & \multicolumn{2}{|c|}{ SDTA } & \multicolumn{2}{|c|}{ SDJN } \\
\hline & Nucleotide & Amino acid & Nucleotide & Amino acid & Nucleotide & Amino acid \\
\hline \multicolumn{7}{|l|}{ ORFV011 } \\
\hline NZ2 (74230714) & 97.4 & 97.6 & 97.3 & 97.1 & 97.4 & 97.9 \\
\hline OV-IA82 (40019122) & 98.3 & 98.1 & 98.2 & 97.6 & 98.3 & 98.4 \\
\hline OV-SA00 (40019123) & 98.2 & 98.7 & 98.0 & 98.1 & 98.3 & 98.9 \\
\hline D1701 (325073632) & 98.2 & 98.4 & 98.1 & 97.9 & 98.4 & 99.2 \\
\hline NA1/11 (KF234407) & 97.4 & 98.4 & 97.2 & 97.9 & 97.1 & 98.1 \\
\hline \multicolumn{7}{|l|}{ ORFV059 } \\
\hline NZ2 (74230714) & 97.3 & 97.3 & 97.3 & 97.0 & 96.8 & 96.7 \\
\hline OV-IA82 (40019122) & 97.2 & 97.3 & 97.2 & 97.0 & 96.6 & 96.7 \\
\hline OV-SA00 (40019123) & 97.5 & 98.8 & 97.5 & 98.5 & 97.1 & 97.7 \\
\hline D1701 (325073632) & 96.0 & 95.9 & 96.0 & 95.6 & 95.8 & 95.3 \\
\hline NA1/11 (KF234407) & 97.1 & 97.3 & 97.1 & 97.0 & 96.6 & 96.7 \\
\hline \multicolumn{7}{|l|}{ ORFV109 } \\
\hline NZ2 (74230714) & 89.0 & 85.0 & 88.6 & 83.8 & 89.0 & 85.0 \\
\hline OV-IA82 (40019122) & 77.0 & 74.1 & 77.0 & 72.8 & 77.4 & 74.1 \\
\hline OV-SA00 (40019123) & 57.4 & 49.1 & 57.4 & 49.1 & 57.4 & 49.1 \\
\hline D1701 (325073632) & 35.6 & 10.8 & 35.4 & 10.8 & 35.6 & 10.8 \\
\hline NA1/11 (KF234407) & 77.0 & 74.1 & 77.0 & 72.8 & 77.4 & 74.1 \\
\hline \multicolumn{7}{|l|}{ ORFV110 } \\
\hline NZ2 (74230714) & 96.0 & 96.4 & 96.2 & 95.2 & 97.0 & 98.2 \\
\hline OV-IA82 (40019122) & 85.1 & 81.8 & 85.7 & 81.8 & 86.1 & 83.6 \\
\hline OV-SA00 (40019123) & 56.9 & 44.8 & 57.3 & 44.8 & 57.9 & 46.1 \\
\hline D1701 (325073632) & 39.4 & 18.2 & 38.9 & 17.6 & 38.7 & 18.2 \\
\hline NA1/11 (KF234407) & 94.6 & 95.2 & 94.8 & 93.9 & 95.6 & 97.0 \\
\hline \multicolumn{7}{|l|}{ ORFV127 } \\
\hline NZ2 (74230714) & 97.0 & 98.4 & 96.8 & 97.8 & 96.4 & 98.4 \\
\hline OV-IA82 (40019122) & 96.1 & 94.6 & 95.9 & 94.1 & 95.5 & 94.6 \\
\hline OV-SA00 (40019123) & 98.2 & 97.8 & 98.2 & 97.3 & 97.8 & 97.8 \\
\hline D1701 (325073632) & 95.9 & 91.9 & 95.9 & 91.9 & 95.5 & 92.4 \\
\hline NA1/11 (KF234407) & 97.1 & 97.3 & 97.0 & 96.8 & 96.6 & 97.3 \\
\hline
\end{tabular}

of SDJN shared $99.1 \%$ nucleotide identity with those of the FJ-GS and FJ-GO strains (Fig. 1A). ORFV059 of the SDLC and SDTA strains clustered together with that of the FJ-YX strain. ORFV059 of SDJN shared $97.4 \%$ nucleotide identity with those of the FJ-GS and FJ-GO strains. ORFV059 and ORFV127 of SDJN, SDTA and SDLC were similar to those of the OV-SA00 strain (Fig. 1B and 1C).

\section{DISCUSSION}

Orf disease is a zoonosis that exists worldwide and has been reported in the past three years $[9,16,18,22,27$, 32]. In China, more than 20 provinces have reported orf disease breakouts during the past few years, and statistics from epidemiological surveys by our group show that there were 51 cases in China in 2014 (data not shown). Shandong Province, which is adjacent to Korea, Japan and other East Asian countries, is famous for sheep and goat breeding and export of mutton products. From 2013 to 2014, goat flocks in three different districts exhibited classic lesions of orf disease (Table 1). As there have been very few breakouts of this disease in Shandong Province, we were eager to know its origin. To date, there has been no report of phylogenetic analysis for the orf virus in Shandong Province. Here, we conducted the epidemiological surveys in different areas in this province, isolated three orf viruses and analyzed the genetic evolution of the coding genes.

The sequences of ORFV011 and ORFV059 are usually used for phylogenetic analysis of orf virus, and these two genes are regarded as epidemiologically relevant sequences $[6,13,35]$. Other genes, like ORFV020 (VIR), are also used in molecular epidemiological studies of ORFV as a marker $[3,27]$. Usually, phylogenetic analysis indicates a hypothetical origin of virus strains, and we also wish to determine the ORFV origin information based on ORFV011 and ORFV059. In the present study, the ORFV strains of SDLC, SDTA and SDJN were most similar to isolates from Fujian Province based on the ORFV011 and ORFV059 gene sequences. We hypothesized that the orf infection in Shandong Province originated in Fujian Province. Detailed survey of trajectory formation for goat sales will be conducted in our future work. According to the phylogenetic relationships based on ORFV011, the SDLC and SDTA strains cluster together with the Gansu, Liaoning, Shanxi, Nantou, Hoping and FJ-YX 

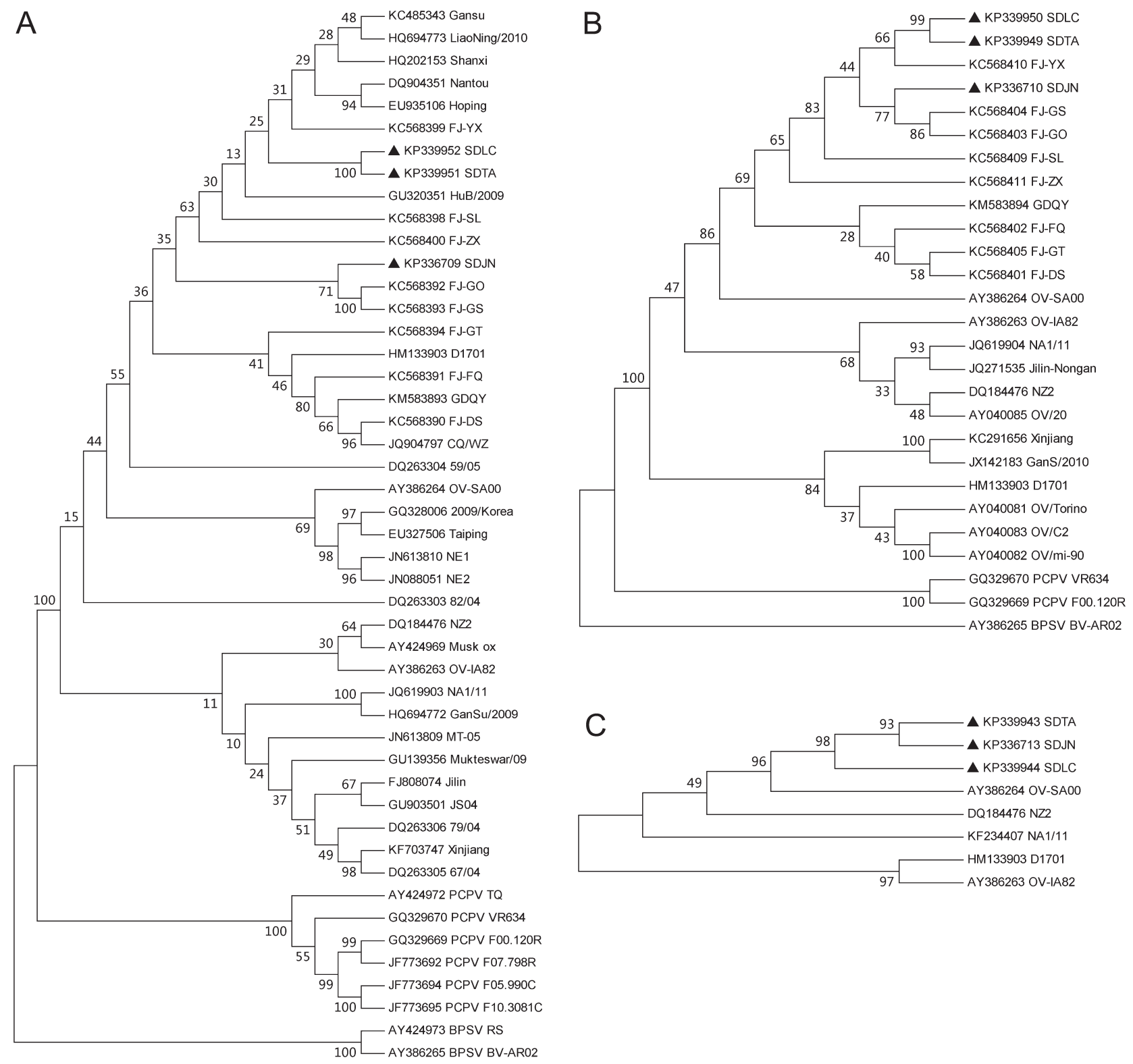

Fig. 1. Phylogenetic analysis based on nucleotide sequences of ORFV011 (A), ORFV059 (B) and ORFV127 (C). The phylogenetic relationship was constructed by the neighbor-joining algorithm using the MEGA 5.0 software. Bootstrap values (\%) are represented at each tree node. Black triangle, strains isolated from Shandong Province.

strains. ORFV011 and ORFV059 of SDJN shared $99.1 \%$ and $97.4 \%$ nucleotide identities with those of the FJ-GS and FJGO strains, respectively. ORFV059 of the SDLC and SDTA strains cluster together with that of FJ-YX. This implies that the SDLC and SDTA strains might originate from the FJ-YX strain and that SDJN may derive from the FJ-GS and FJ-GO strains. We hypothesized that these three orf virus strains originated in Fujian Province and formed a complex group of viruses in Shandong Province.

Because of the role of IL-10 in limitation and termination of the inflammatory response during tissue repair, ORFV127, which encoded an IL-10-like protein, is also regarded as having a function related to immune evasion in ORFV infection $[10,30]$. The phylogenetic analysis of the ORFV127 genes of these three isolated viruses indicated that they were similar to that of the OV-SA00 strain. We hypothesized that the pathogenesis of these three virus strains may be similar to that of OV-SA00 based on the function of ORFV127. ORFV109 and ORFV110 encode envelope type II glycoproteins, and these two genes are highly variable and unsuitable for virus orthological analysis [9]. We will continue to isolate and characterize ORFV strains from different locations 
in Shandong Province to obtain more detailed information.

In summary, we isolated three orf virus strains from different districts in Shandong Province. Based on the sequences of the ORFV011, ORFV059 and ORFV127 genes, they were novel ORFV strains, and phylogenetic analysis revealed that they clustered together with Fujian strains and formed a complex group of viruses in Shandong Province. Taken together, new phylogenetic information about ORFV strains in Shandong Province were obtained, and the data reported here will be helpful for further research about ORFV and its comprehensive prevention and control in East China.

ACKNOWLEDGMENTS. This work was partially supported by the Development Program for Excellent Young Teachers in Guangdong Province (Yq2013025) and Program for Bovine Industry of Shandong Province (SDAIT-12-011-04).

\section{REFERENCES}

1. Billinis, C., Mavrogianni, V. S., Spyrou, V. and Fthenakis, G. C. 2012. Phylogenetic analysis of strains of Orf virus isolated from two outbreaks of the disease in sheep in Greece. Virol. J. 9: 24-32. [Medline] [CrossRef]

2. Centers for Disease Control and Prevention (CDC) 2012. Human Orf virus infection from household exposures - United States, 2009-2011. MMWR Morb. Mortal. Wkly. Rep. 61: 245-248. [Medline]

3. Chan, K. W., Hsu, W. L., Wang, C. Y., Yang, C. H., Lin, F. Y., Chulakasian, S. and Wong, M. L. 2009. Differential diagnosis of orf viruses by a single-step PCR. J. Virol. Methods 160: 85-89. [Medline] [CrossRef]

4. Chan, K. W., Lin, J. W., Lee, S. H., Liao, C. J., Tsai, M. C., Hsu, W. L., Wong, M. L. and Shih, H. C. 2007. Identification and phylogenetic analysis of orf virus from goats in Taiwan. Virus Genes 35: 705-712. [Medline] [CrossRef]

5. Chan, K. W., Yang, C. H., Lin, J. W., Wang, H. C., Lin, F. Y., Kuo, S. T., Wong, M. L. and Hsu, W. L. 2009. Phylogenetic analysis of parapoxviruses and the C-terminal heterogeneity of viral ATPase proteins. Gene 432: 44-53. [Medline] [CrossRef]

6. Chi, X., Zeng, X., Hao, W., Li, M., Li, W., Huang, X., Wang, S. and Luo, S. 2013. Heterogeneity among orf virus isolates from goats in Fujian Province, Southern China. PLoS ONE 8: e66958. [Medline] [CrossRef]

7. de Oliveira, C. H., Assis, F. L., Neto, J. D., Oliveira, C. M., Lopes, C. T., Bomjardim, H. A., Vinhote, W. M., Silva, A. G., Abrahão, J. S. and Kroon, E. G. 2012. Multifocal cutaneous ORF virus infection in goats in the Amazon region, Brazil. Vector Borne Zoonotic Dis. 12: 336-340. [Medline] [CrossRef]

8. Delhon, G., Tulman, E. R., Afonso, C. L., Lu, Z., de la ConchaBermejillo, A., Lehmkuhl, H. D., Piccone, M. E., Kutish, G. F. and Rock, D. L. 2004. Genomes of the parapoxviruses ORF virus and bovine papular stomatitis virus. J. Virol. 78: 168-177. [Medline] [CrossRef]

9. Duan, C., Liao, M., Wang, H., Luo, X., Shao, J., Xu, Y., Li, W., Hao, W. and Luo, S. 2015. Identification, phylogenetic evolutionary analysis of GDQY orf virus isolated from Qingyuan City, Guangdong Province, southern China. Gene 555: 260-268. [Medline] [CrossRef]

10. Fleming, S. B., Haig, D. M., Nettleton, P., Reid, H. W., McCaughan, C. A., Wise, L. M. and Mercer, A. 2000. Sequence and functional analysis of a homolog of interleukin-10 encoded by the parapoxvirus orf virus. Virus Genes 21: 85-95. [Medline]
[CrossRef]

11. Guo, J., Rasmussen, J., Wünschmann, A. and de La ConchaBermejillo, A. 2004. Genetic characterization of orf viruses isolated from various ruminant species of a zoo. Vet. Microbiol. 99: 81-92. [Medline] [CrossRef]

12. Haig, D. M. and Mercer, A. A. 1998. Ovine diseases. Orf. Vet. Res. 29: 311-326. [Medline]

13. Hautaniemi, M., Ueda, N., Tuimala, J., Mercer, A. A., Lahdenperä, J. and McInnes, C. J. 2010. The genome of pseudocowpoxvirus: comparison of a reindeer isolate and a reference strain. $J$. Gen. Virol. 91: 1560-1576. [Medline] [CrossRef]

14. Hautaniemi, M., Vaccari, F., Scagliarini, A., Laaksonen, S., Huovilainen, A. and McInnes, C. J. 2011. Analysis of deletion within the reindeer pseudocowpoxvirus genome. Virus Res. 160: 326-332. [Medline] [CrossRef]

15. Hosamani, M., Bhanuprakash, V., Scagliarini, A. and Singh, R. K. 2006. Comparative sequence analysis of major envelope protein gene (B2L) of Indian orf viruses isolated from sheep and goats. Vet. Microbiol. 116: 317-324. [Medline] [CrossRef]

16. Joseph, R. H., Haddad, F. A., Matthews, A. L., Maroufi, A., Monroe, B. and Reynolds, M. 2015. Erythema multiforme after orf virus infection: a report of two cases and literature review. Epidemiol. Infect. 143: 385-390. [Medline] [CrossRef]

17. Kottaridi, C., Nomikou, K., Teodori, L., Savini, G., Lelli, R., Markoulatos, P. and Mangana, O. 2006. Phylogenetic correlation of Greek and Italian orf virus isolates based on VIR gene. Vet. Microbiol. 116: 310-316. [Medline] [CrossRef]

18. Kumar, N., Wadhwa, A., Chaubey, K. K., Singh, S. V., Gupta, S., Sharma, S., Sharma, D. K., Singh, M. K. and Mishra, A. K. 2014. Isolation and phylogenetic analysis of an orf virus from sheep in Makhdoom, India. Virus Genes 48: 312-319. [Medline] [CrossRef]

19. Li, H., Ning, Z., Hao, W., Zhang, S., Liao, X., Li, M. and Luo, S. 2012. Identification and characterization of monoclonal antibodies against the ORFV059 protein encoded by Orf virus. Virus Genes 44: 429-440. [Medline] [CrossRef]

20. Li, H., Zhu, X., Zheng, Y., Wang, S., Liu, Z., Dou, Y., Li, H., Cai, X. and Luo, X. 2013. Phylogenetic analysis of two Chinese orf virus isolates based on sequences of B2L and VIR genes. Arch. Virol. 158: 1477-1485. [Medline] [CrossRef]

21. Li, W., Hao, W., Peng, Y., Duan, C., Tong, C., Song, D., Gao, F., Li, M., Rock, D. L. and Luo, S. 2015. Comparative genomic sequence analysis of Chinese orf virus strain NA1/11 with other parapoxviruses. Arch. Virol. 160: 253-266. [Medline] [CrossRef]

22. Li, W., Ning, Z., Hao, W., Song, D., Gao, F., Zhao, K., Liao, X., Li, M., Rock, D. L. and Luo, S. 2012. Isolation and phylogenetic analysis of orf virus from the sheep herd outbreak in northeast China. BMC Vet. Res. 8: 229. [Medline] [CrossRef]

23. Liu, Y., Shao, H., Cheng, R., Li, M., Ren, R., Li, H., Li, G. and Fu, D. 2007. Establish and Application of PCR Detection Method to Contagious Pustular Dermatitis Virus. Jilin $\mathrm{Xu} M u$ Shou Yi 3: 7-9 (in Chinese).

24. McGuire, M. J., Johnston, S. A. and Sykes, K. F. 2012. Novel immune-modulator identified by a rapid, functional screen of the parapoxvirus ovis (Orf virus) genome. Proteome Sci. 10: 4. [Medline] [CrossRef]

25. Mercer, A. A., Ueda, N., Friederichs, S. M., Hofmann, K., Fraser, K. M., Bateman, T. and Fleming, S. B. 2006. Comparative analysis of genome sequences of three isolates of Orf virus reveals unexpected sequence variation. Virus Res. 116: 146-158. [Medline] [CrossRef]

26. Ning, Z., Zheng, Z., Hao, W., Duan, C., Li, W., Wang, Y., Li, M. 
and Luo, S. 2013. The $\mathrm{N}$ terminus of orf virus-encoded protein 002 inhibits acetylation of NF- $\mathrm{kB}$ p65 by preventing $\operatorname{Ser}^{276}$ phosphorylation. PLoS ONE 8: e58854. [Medline] [CrossRef]

27. Oem, J. K., Chung, J. Y., Kim, Y. J., Lee, K. K., Kim, S. H., Jung, B. Y. and Hyun, B. H. 2013. Isolation and characterization of orf viruses from Korean black goats. J. Vet. Sci. 14: 227-230. [Medline] [CrossRef]

28. Oem, J. K., Roh, I. S., Lee, K. H., Lee, K. K., Kim, H. R., Jean, Y. H. and Lee, O. S. 2009. Phylogenetic analysis and characterization of Korean orf virus from dairy goats: case report. Virol. J. 6: 167. [Medline] [CrossRef]

29. Wang, G., Shang, Y., Wang, Y., Tian, H. and Liu, X. 2013. Comparison of a loop-mediated isothermal amplification for orf virus with quantitative real-time PCR. Virol. J. 10: 138. [Medline] [CrossRef]

30. Wise, L. M., Stuart, G. S., Real, N. C., Fleming, S. B. and Mercer, A. A. 2014. Orf virus IL-10 accelerates wound healing while limiting inflammation and scarring. Wound Repair Regen. 22: 356-367. [Medline] [CrossRef]
31. Yang, H., Meng, Q., Qiao, J., Peng, Y., Xie, K., Liu, Y., Zhao, H., Cai, X. and Chen, C. 2014. Detection of genetic variations in Orf virus isolates epidemic in Xinjiang China. J. Basic Microbiol. 54: 1273-1278. [Medline] [CrossRef]

32. Zhang, K., Liu, Y., Kong, H., Shang, Y. and Liu, X. 2014. Human infection with ORF virus from goats in China, 2012. Vector Borne Zoonotic Dis. 14: 365-367. [Medline] [CrossRef]

33. Zhang, K., Liu, Y., Kong, H., Shang, Y. and Liu, X. 2014. Comparison and phylogenetic analysis based on the B2L gene of orf virus from goats and sheep in China during 2009-2011. Arch. Virol. 159: 1475-1479. [Medline] [CrossRef]

34. Zhang, K., Shang, Y., Jin, Y., Wang, G., Zheng, H., He, J., Lu, Z. and Liu, X. 2010. Diagnosis and phylogenetic analysis of Orf virus from goats in China: a case report. Virol. J. 7: 78. [Medline] [CrossRef]

35. Zhao, K., Song, D., He, W., Lu, H., Zhang, B., Li, C., Chen, K. and Gao, F. 2010. Identification and phylogenetic analysis of an Orf virus isolated from an outbreak in sheep in the Jilin province of China. Vet. Microbiol. 142: 408-415. [Medline] [CrossRef] 